\title{
Terapi Suportif Meningkatkan Motivasi untuk Melakukan Operasi Katarak pada Pasien Katarak di Wilayah Kerja Puskesmas Tempurejo Kabupaten Jember (Supportive Therapy to Increase Motivation to Undergo Cataract Surgery on Patients with Cataract in the Area of Public Health Center of Tempurejo Jember)
}

\author{
Siswoyo, Murtaqib, Tri Buana Ratna Sari \\ Fakultas Keperawatan Universitas Jember \\ JI. Kalimantan No. 37 Kampus Tegal Boto Jember Telp./Fax. (0331) 323450 \\ email: siswoyo.psik@unej.ac.id
}

\begin{abstract}
Cataract was an eye disease that could induce cloudy eye lens. The lack of motivation within inner self caused patients to be reluctant to undergo cataract removal surgery which could make blindness rate keep increasing. Supportive therapy was a form of therapy used on individuals on patients with difficulties in solving their problems. The purpose of this study was to analyze the effects of supportive therapy on motivation to undergo cataract removal surgery on patients with cataract. This study used pre-experimental, one-group pre-test design. Sample-obtaining technique was purposive sampling with 15 patients. Supportive therapy was given in three meetings. The first and second session were grouped together as one meeting with the duration of 30-35 minutes for each session. The third and fourth session were grouped together as one meeting with the duration of 30-35 minutes for each session. Data were analyzed by using dependent $t$ test and showed a difference between pre-test and post-test with $p$ value $=0,001$ ( $p$ value $<0,05$ ). The result showed that there was an effect of supportive therapy on motivation to undergo cataract removal surgery in patients with cataract. This study suggests nurses to give supportive therapy to patients with physical or psychological problem.
\end{abstract}

Keywords: cataract, supportive therapy, motivation

\begin{abstract}
Abstrak
Katarak adalah penyakit mata yang dapat mengakibatkan kekeruhan pada lensa mata. Kurangnya motivasi di dalam diri sendiri mengakibatkan pasien enggan melakukan operasi katarak yang dapat menimbulkan angka kebutaan terus meningkat. Terapi suportif adalah bentuk terapi yang digunakan pada individu yang memiliki kesulitan dalam menyelesaikan masalahnya. Tujuan dari penelitian ini untuk menganalisis pengaruh terapi suportif terhadap motivasi untuk melakukan operasi katarak. Penelitian ini menggunakan pre-experimental, one-group pre-test design. Teknik pengambilan sampel adalah purposive sampling dengan menggunakan 15 responden pasien katarak. Terapi suportif diberikan dalam 3 kali pertemuan. Sesi satu dan dua dijadikan satu pertemuan dengan durasi 30-35 menit pada masing-masing sesi. Sesi tiga dan empat dibuat satu kali pertemuan dengan durasi 30-35 menit pada masing-masing sesi. Hasil data dianalisis menggunakan uji $t$ dependent menunjukan adanya perbedaan antara pretest dan posttest dengan hasil dari $p$-value 0,001 ( $p$-value $<0,05$ ). Hasil dari penelitian ini menunjukkan bahwa terdapat pengaruh pemberian terapi suportif terhadap motivasi untuk melakukan operasi katarak. Saran dari penelitian kepada perawat adalah agar dapat menerapkan terapi suportif untuk mengatasi masalah fisik dan psikologis pada pasien katarak.
\end{abstract}

Kata kunci : katarak, terapi suportif, motivasi 


\section{Pendahuluan}

Kebutaan dan gangguan penglihatan merupakan masalah yang harus segera ditangani karena mempengaruhi rendahnya kualitas sumber daya manusia sehingga meningkatkan biaya kesehatan [1]. Katarak adalah suatu penyakit mata dimana terjadi kekeruhan pada lensa mata. Lensa mata normalnya transparan, jernih dan dilalui cahaya menuju retina. Kekeruhan pada lensa mata dapat mengakibatkan lensa tidak transparan, sehingga pupil berwarna putih dan abu-abu [2].

Sekitar 45 juta dari 180 juta orang penduduk di dunia mengalami kebutaan. Indonesia sendiri menjadi peringkat kedua dengan kejadian kebutaan tertinggi di dunia setelah Ethiopia [3]. Jenis kebutaan yang banyak dialami penduduk di dunia adalah katarak 51\%, glaucoma 8\%, Age related Macular Degeneration (AMD) 5\%, kekeruhan kornea 4\%, gangguan refraksi $3 \%$,trachoma 3\%, Retinopati diabetic $1 \%$. Sebesar $21 \%$ tidak dapat ditentukan penyebabnya dan $4 \%$ adalah gangguan penglihatan sejak masa kanak-kanak [4]. Data Dinas Kesehatan Kabupaten Jember didapatkan data prevalensi katarak tertingi di Kabupaten Jember yang menduduki peringkat pertama yaitu puskesmas Tempurejo dengan jumlah 2010 pasien katarak, urutan kedua yaitu Sukorejo dengan jumlah 1905 pasien katarak, dan urutan ketiga di Gumukmas dengan jumlah 400 pasien katarak [5]. Masih banyak penderita katarak yang belum operasi di karenakan tidak mengetahui menderita katarak $51,6 \%$, karena tidak mampu membiayai $11,6 \%$, karena takut operasi $8,1 \%$ [3].

Berdasarkan data dari penelitian, penyebab pasien tidak mau operasi antara lain biaya operasi mahal, takut untuk operasi, dan karena usianya sudah tua pasien tidak perlu untuk operasi katarak. Berdasarkan data Puskesmas Tempurejo pada Bulan April 2017 terdapat 45 pasien katarak yang belum operasi.

Faktor pendukung untuk melakukan operasi katarak antara lain motivasi $18 \%$, biaya operasi gratis $18 \%$, dukungan keluarga $15 \%$, dan dukungan masyarakat $14 \%$ [6]. Penelitian yang dilakukan oleh Rahmadani dengan adanya motivasi dapat mempengaruhi pasien untuk operasi katarak menunjukkan $68,27 \%$. Semakin baik dorongan yang diberikan akan memberikan motivasi pasien untuk operasi katarak.

Terdapat beberapa intervensi yang dapat dilakukan untuk meningkatkan motivasi di dalam dirinya salah satunya intervensi terapi suportif. Terapi suportif adalah suatu terapi yang dipilih dan langsung digunakan pada individu maupun kelompok yang mempunyai gejala psikologis yang rendah. Terapi suportif mampu menolong individu untuk bisa mempertahankan kondisi psikologis pasien dalam mengatasi suatu masalah yang sedang dihadapi [7].

Melihat fenomena yang terdapat di Puskesmas Tempurejo setelah dilakukannya studi pendahuluan tersebut membuat peneliti ingin melakukan penelitian mengenai terapi suportif agar pasien katarak yang berada di Wilayah Kerja Puskesmas Tempurejo memiliki motivasi didalam dirinya untuk mengubah pola pikir negatif mengenai pentingnya operasi katarak. Terapi suportif menekankan pada individu daripada kelompok karena ketika melakukan komunikasi akan lebih mudah dan berfokus terhadap masalah yang dimiliki oleh pasien terutama yang motivasinya rendah atau kesulitan dalam menyelesaikan masalahnya

\section{Metode Penelitian}

Jenis penelitian ini adalah penelitian preeksperimental dengan menggunakan pendekatan one-group pretest posttest design. Teknik pengambilan sampel menggunakan purposive sampling. Jumlah sampel pada penelitian ini sebanyak 15 pasien katarak yang belum melakukan operasi katarak. Penelitian ini dilakukan di Wilayah Kerja Puskesmas Tempurejo Kabupaten Jember. Waktu penelitian dilakukan pada bulan Mei 2017 sampai dengan Juli 2017.

Pemberian terapi suportif dilakukan dalam 3 kali pertemuan. Terapi suportif diberikan sebanyak 4 sesi masing-masing sesi diberikan sebanyak 35 menit per sesi. Teknik pengumpulan data dalam penelitian ini menggunakan nilai motivasi untuk melakukan operasi yang diukur dengan kuisioner. Data dianalisis dengan menggunakan uji $t$ dependent.

\section{Hasil Penelitian Karakteristik Responden}

Tabel 1. Responden Menurut Usia pada pasien Katarak di Kecamatan Tempurejo Kabupaten Jember pada bulan Mei 2017 ( $n=15)$

\begin{tabular}{|l|l|r|l|}
\hline Variabel & \multicolumn{1}{|c|}{ Mean } & SD & \multicolumn{1}{c|}{ Min-Mak } \\
\hline Usia (Tahun) & 59.73 & 5.824 & $52-72$ \\
\hline
\end{tabular}


Tabel 2. Distribusi Responden Menurut Jenis Kelamin, Pendidikan, dan Pekerjaan pada pasien katarak di Kecamatan Tempurejo Kabupaten Jember (Mei 2017; $\mathrm{n}: 15)$

\begin{tabular}{|l|l|l|}
\hline \multicolumn{1}{|c|}{ Variabel } & Frekuensi & Persentase $\%$ \\
\hline Jenis Kelamin & & \\
Laki-laki & 6 & 40,0 \\
Perempuan & 9 & 60,0 \\
\hline Total & 15 & 100 \\
\hline Pendidikan & & \\
Tidak Sekolah & 5 & 33,3 \\
SD & 4 & 26,7 \\
SMP & 2 & 13,3 \\
SMA/SMK & 4 & 26,7 \\
\hline Total & 15 & 100 \\
\hline Peekerjaan & & \\
Tidak Bekerja & 5 & 33,3 \\
Petani/Buruh & 2 & 13,3 \\
Wiraswasta & 3 & 20,0 \\
Lain-lain & 5 & 33,3 \\
\hline Total & 15 & 15 \\
\hline
\end{tabular}

Tabel 3. Motivasi Sebelum diberikan Terapi Suportif pada pasien katarak di Wilayah Kerja Puskesmas Tempurejo Kabupaten Jember

\begin{tabular}{|l|l|l|l|}
\hline \multicolumn{1}{|c|}{ Variabel } & \multicolumn{1}{c|}{ Mean } & \multicolumn{1}{c|}{ SD } & Min-Maks \\
\hline $\begin{array}{l}\text { Motivasi } \\
\text { sebelum }\end{array}$ & 62,80 & 2757 & $58-67$ \\
\hline
\end{tabular}

Tabel 4 Motivasi Setelah diberikan Terapi Suportif pada pasien katarak di Wilayah Kerja Puskesmas Tempurejo Kabupaten Jember

\begin{tabular}{|l|l|l|l|}
\hline \multicolumn{1}{|c|}{ Variabel } & \multicolumn{1}{|c|}{ Mean } & \multicolumn{1}{c|}{ SD } & \multicolumn{1}{c|}{ Min-Maks } \\
\hline $\begin{array}{l}\text { Motivasi } \\
\text { setelah }\end{array}$ & 68,53 & 2,295 & $63-71$ \\
\hline
\end{tabular}

Tabel 5 Hasil Uji $\mathrm{t}$ dependen Motivasi untuk Melakukan Operasi Katarak pada pasien katarak di Wilayah Kerja Puskesmas Tempurejo Kabupaten Jember

\begin{tabular}{|l|c|c|c|}
\hline \multicolumn{1}{|c|}{ Variabel } & Mean & $\mathbf{t}$ & $\mathbf{P}$ \\
\hline $\begin{array}{l}\text { Motivasi: Pretest } \\
\text { Postets }\end{array}$ & $-5,733$ & -7.433 & 0,001 \\
\hline
\end{tabular}

Hasil analisis pada tabel 5 terdapat pengaruh pemberian terapi suportif terhadap motivasi untuk melakukan operasi katarak dapat dilihat setelah dilakukan uji $t$ dependent menunjukkan bahwa $\mathrm{t}$ hitung $-7,433$ dengan nilai probalitias 0,001 ( $p<$ $0,05)$, maka Ho ditolak yang artinya terdapat perbedaan motivasi untuk melakukan operasi katarak sebelum dan setelah diberikan intervensi terapi suportif. Nilai negative pada mean different $(-5,733)$ menunjukkan adanya peningkatan motivasi untuk melakukan operasi katarak.

\section{Pembahasan \\ Karakteristik Responden}

Hasil penelitian menunjukkan usia responden rata-rata 59,73 tahun dengan usia terendah 52 tahun dan usia tertinggi 72 tahun. Berdasarkan data tersebut dapat disimpulkan bahwa yang mengalami penyakit katarak di wilayah Kerja Puskesmas Tempurejo berusia 55 tahun keatas. Menurut penelitian Erman. Penyebab terjadinya penyakit katarak karena bertambahnya usia sekitar $90 \%$ penderita katarak terjadi pada usia di atas 50 tahun [8].

Pada penelitian ini responden berjenis kelamin perempuan yang sebanyak 9 orang $(60,0 \%)$ dibandingkan dengan laki-laki sebanyak 6 orang $(40,0 \%)$. Namun pada penelitian ini tidak sejalan dengan Hanok, dkk yang menyebutkan faktor-faktor yang berhubungan dengan kejadian katarak mengatakan bahwa paling banyak adalah responden berjenis kelamin laki-laki berjumlah 72 responden $(51,4 \%)$ dibandingkan dengan perempuan sebanyak 68 responden $(48,6 \%)$ [9]. Namun ada yang berpendapat bahwa pada laki-laki juga banyak yang menderita katarak dikarenakan mereka banyak yang bekerja di luar ruangan yang setiap harinya sering terpapar dengan sinar ultraviolet (UV) tanpa menggunakan Alat Pelindung Diri (APD) yang dapat mengakibatkan tingkat kematangan kataraknya mengalami peningkatan. Pada penelitian ini tidak dapat dijadikan acuan karena jumlah responden pada penelitian ini sedikit dimana peneliti hanya menggunakan 15 responden pasien katarak yang belum melakukan operasi.

Responden berdasarkan pendidikan rata-rata pendidikan tertinggi responden katarak di wilayah Kerja Puskesmas Tempurejo yaitu tidak sekolah sebesar 5 orang $(33,3 \%)$. Menurut penelitian Ulandari [10], pendidikan rendah dapat meningkatkan terjadinya katarak sebesar 25 kali dibandingkan dengan pendidikan tinggi. Tingkat pendidikannya seseorang akan mempengaruhi pola pikir dan juga pemahaman mengenai penyakit katarak dan juga pengobatannya. Tingkat pendidikan yang baik dapat mempengaruhi tingkat pengetahuan masyarakat dalam memahami suatu informasi tentang katarak. Pendidikan mempengaruhi 
proses belajar, semakin tinggi pendidikan seseorang maka semakin mudah seseorang untuk menerima informasi.

Menurut data yang diambil rata-rata pasien katarak pada penelitian menunjukkan tidak bekerja dan lain-lain mempunyai hasil yang sama yaitu sekitar 5 orang $(33,3 \%)$. Pada pasien yang tidak bekerja rata-rata mereka dulu bekerja sebagai petani. Berdasarkan data yang diambil oleh peneliti di wilayah Kerja Puskesmas Tempurejo mereka bekerja sebagai kuli bangunan, bengkel dan juga sebagian mereka yang tidak bekerja dulunya sebagai petani dan buruh. Menurut penelitian yang dilakukan oleh Tana [11], pekerjaan yang memiliki resiko terjadinya katarak seperti kelompok petani, nelayan, dan juga buruh resiko terkena katarak 2,5 kali $(16 \%)$ dibandingkan dengan masyarakat yang pekerjaannya sebagai pegawai. Tingginya katarak yang terjadi pada kelompok pekerja yang berada di luar ruangan yang menyebabkan adanya pajanan kronis sinar matahari karena merupakan salah satu faktor risiko katarak. Prevalensi katarak pada pekerja di luar ruangan lebih tinggi (1,3 kali) dibandingkan dengan didalam ruang.

\section{Nilai Motivasi Melakukan Operasi Katarak Sebelum Terapi Suportif}

Berdasarkan tabel.3 sebelum diberikan terapi suportif yaitu 62,80 dari nilai terendah 58 dan tertinggi 67. Dari hasil penelitian di atas bahwa salah satu penyebab pasien tidak melakukan operasi katarak karena rasa takut, kurangnya biaya dan kurangnya motivasi internal maupun eksternal yang dapat mengubah pola pikir negatif mengenai operasi katarak tersebut. Adanya motivasi dapat memicu timbulnya perubahan di dalam individu mengenai penyakit katarak yang memungkinkan pasien tersebut untuk bertindak atau berbuat lebih baik dengan cara pasien dapat operasi katarak. Berdasarkan penjelasan di atas peneliti berpendapat menurut informasi yang didapatkan di lapangan bahwa sebagian masyarakat yang di wilayah Kerja Puskesmas Tempurejo memiliki motivasi yang rendah untuk operasi katarak karena kurangnya dari motivasi di dalam dirinya untuk bisa beraktivitas lagi tanpa adanya gangguan penglihatan, kurangnya dukungan dari keluarga yang membuat pasien katarak memiliki motivasi rendah dan juga ekonomi rendah mempengaruhi motivasi pasien katarak, hal tersebut juga akan mempengaruhi psikologis pasien dalam menyelesaikan masalah tersebut.

Motivasi adalah sesuatu yang menunjukkan proses perilaku, serta tingkah laku yang di timbulkan oleh situasi tersebut agar dapat menimbulkan perilaku atau perbuatan sesuai dengan tujuan akhir [12]. Motivasi dibedakan menjadi dua macam, yaitu motivasi yang berasal dari dalam individu dan motivasi ekstrinsik merupakan motivasi yang bersal dari luar individu (Suarli, 2009).

\section{Nilai Motivasi Melakukan Operasi Katarak Setelah Terapi Suportif}

Berdasarkan tabel 4 nilai rata-rata setelah diberikan intervensi terapi suportif yaitu 68,53 dengan nilai maksimum 71 hal ini menunjukkan bahwa nilai rata rata setelah diberikan terapi suportif hampir mendekati nilai maksimum. Hal tersebut juga dipengaruhi oleh tiga indikator motivasi yaitu daya tarik, usaha dan prestasi , prestasi dan imbalan. Hasil dari uji dependent $t$-test tet diperoleh nilai $p$ value 0 , $001(p<0,05)$ yang artinya ada pengaruh terapi suportif terhadap motivasi untuk melakukan operasi katarak pada pasien katarak di wilayah kerja Puskesmas Tempurejo Kabupaten Jember.

Peningkatan terapi suportif yang diberikan pada pasien katarak dimana sebelum diberikan terapi suportif beberapa pasien sudah memiliki motivasi untuk operasi akan tetapi sebagian dari pasien tersebut terkendala pada faktor internal dan eksternal. Hal itu dikarenakan karena pada saat pemberian terapi terkendala waktu, harus diulang karena ada beberapa pasien katarak yang tidak mengerti. Pada saat diberikan terapi suportif hampir semua terjadi peningkaatan terhadap skor nilai motivasi sebelum dan sesudah diberikan terapi suportif.

Pemberian terapi suportif ini dapat meningkatkan kognitif pasien karena memberikan informasi mengenai katarak dan membantu seseorang untuk memberikan arahan kepada pasiem yang tidak dapat mengatasi permasalahannya. Hal tersebut dapat meningkatkan daya tarik pasien katarak. Daya tarik merupakan nilai yang diberikan seseorang terhadap hasil yang diharapkan seseorang tersebut. Usaha untuk berprestasi merupakan hasil yang diharapkan oleh seseorang yang berkaitan sejauh mana usaha seseorang tersebut untuk dapat melakukan hasil yang diinginkannya [13].

Terapi Suportif adalah suatu terapi yang dipilih dan langsung digunakan pada individu maupun kelompok yang mempunyai gejala psikologis yang rendah untuk menolong individu bisa mempertahankan psikologis 
pasien dalam mengatasi suatu masalah yang sedang dihadapi [7]. Menurut penelitian Swasti terjadi penurunan ansietas sebelum dan sesudah diberikan terapi suportif dengan hasil pengujian paired $t$ test pada kelompok intervensi membuktikan terjadi penurunan secara bermakna ( $p$-value $0,000<0,05$ ) sebesar 0,821 dengan standar deviasi $-0,22$ yang tingkat ansietas sedang menjadi tingkat ansietas ringan [14]. Sejalan dengan penelitian Budiningtyas [15] terhadap intensi hasil uji dependent t-test di dapatkan nilai ( $p$-value $0,000<0,05$ ) sehingga dapat disimpulkan terdapat intensi setelah diberikan terapi suportif. Dengan begitu setelah diberikan intervensi terapi suportif terjadi perbedaan sebelum dan sesudah sebesar 12,47 meningkat menjadi 13,87 pada nilai post tesnya. Berdasarkan penelitian berpendapat bahwa terapi suportif ini dapat membantu mengatasi masalah psikologis pasien yang mempunyai motivasi rendah, tidak dapat menyelesaikan permasalahan yang dimiliki oleh pasien dengan adanya terapi suporti ini menjadi terapi pendukung untuk membantu mengatasi permasalahan pasien, dapat menguatkan daya mental yang ada, dengan membangun hubungan yang bersifat suportif antara pasien dan terapis. Sehingga pasien memiliki motivasi untuk melakukan operasi katarak.

\section{Pengaruh Terapi Suportif Terhadap Motivasi Untuk Melakukan Operasi Katarak}

Berdasarkan Tabel 5 didapatkan rata-rata motivasi untuk melakukan operasi katarak sebesar $-5,733$. Hasil uji $t$ dependent diketahui nilai $p$-value $0,001 \quad(p<0,05)$ hal tersebut menunjukkan adanya pengaruh pemberian terapi suportif terhadap motivasi untuk melakukan operasi katarak pada pasien katarak di Wilayah Kerja Puskesmas Tempurejo Kabupaten Jember.

Terapi suportif ini terdiri dari tiga prinsip dasar yaitu ekspresi perasaan, dukungan sosial, dan keterampilan manajemen kognitif. Dukungan sosial dan juga perasaan dapat memberikan dorongan untuk dapat melakukan sesuatu yang ada pada pasien sehingga dapat mengembangkan sumber pendukung yang baru pada pasien [13].

Ekspresi dan perasaan pasien katarak dapat menceritakan apa yang selama ini menjadi kendala belum melakukan operasi baik dari pengalamanya maupun masalah-masalah yang tidak dapat diselesaikan dan juga terapi suportif dapat meningkatkan kemampuan adaptasi pasien terhadap situasi kehidupan, membangun kekuatan ego, dan kemampuan dalam penyelesaian masalah [13]. Hal tersebut sesuai dengan teori behavioristik bahwa perilaku terbentuk melalui perkaitan antara stimulus dan respon yang menyebabkan seseorang untuk berubah lebih banyak dipengaruhi oleh faktor lingkungan. Sehingga dengan begitu ketika pasien diberikan penjelasan mengenai pentingnya operasi katarak, dan dapat membantu untuk menyelesaikan permasalahan pasien yang belum melakukan operasi katarak pasien dapat mempunyai motivasi untuk melakukan operasi.

Motivasi adalah Adanya pendorong yang mengakibatkan seseorang mau dan rela untuk mengerahkan kemampuannya, tenaga, dan waktunya untuk berbagai kegiatan yang menjadi tujuannya dan menunaikan kewajibanya, dalam rangka pencapaian tujuan yang telah ditentukan sebelumnya [13]. Motivasi tersebut memberikan energi positif dalam diri seseorang yang mendorong keinginan individu untuk melakukan tindakan atau tugas guna memenuhi tujuan yang sudah ditentukan. Jika sesorang memiliki tingkat motivasi yang rendah, maka individu tersebut membutuhkan intervensi yang dapat meningkatkan motivasi untuk menjalani berbagai proses dalam hidupnya. Individu yang memiliki motivasi intrinsik yang kuat akan melakukan proses perubahan apabila terjadi gangguan pada dirinya untuk melakukan pembenahan sehingga sesuai dengan apa yang diinginkan untuk mendapatkan keadaan yang lebih baik [16].

Tujuan dari terapi suportif ini membantu mengatasi masalah dengan begitu akan berfokus pada pasien, dan menolong pasien untuk menentukan arah [7]. Dalam pemberian terapi suportif ini berespon langsung terhadap masalah yang sedang dihadapi pasien saat ini yaitu takut, tidak mempunyai biaya, tidak mengetahui mengenai katarak untuk melakukan operasi katarak sehingga pasien dapat menyelesaikan masalah, meningkatkan mekanisme koping dalam melakukan suatu tindakan, mencegah adanya komplikasi, dan membantu pasien mengubah pola pikir negatif sehingga pasien mempunyai pemikiran sehat mengenai pentingnya operasi katarak.

\section{Simpulan dan Saran}

Terdapat pengaruh terapi suportif terhadap motivasi melakukan operasi katarak pada pasien katarak. Terapi suportif ini dapat meningkatakan motivasi. Perawat dapat melaksanakan intervensi terapi suportif untuk 
melakukan deteksi kendala dan masalah yang dialami oleh penderita katarak dan keluarganya sehingga dapat meningkatkan motivasi pasien untuk menyelesaikan masalahnya. Pada penelitian selanjutnya diharapkan untuk menerapkan penelitian quasi-eksperimen karena dapat mengetahui hasil yang maksimal mengenai motivasi seseorang sebelum dan sesudah diberikan terapi suportif jika ada kelompok kontrol.

\section{Daftar Pustaka}

[1] Arimbi AT. Faktor-faktor yang berhubungan dengan katarak degeneratif di RSUD Budhi Asih. 2011. Jakarta: Universitas Indonesia; 2014 [disitasi 25 Februari 2017]. Available from

https://ejournal.unsrat.ac.id/index.php/jkp/a rticle

[2] Ilyas S. Ilmu penyakit mata. Jakarta: Balai Penerbit FKUI; 2007

[3] WHO. Cataract. 2013. [internet] USA. [cited 2017 April 27]. Available from:

http://www.who.int/mediacentre/factsheets/f s213/en

[4] Indonesia. KEMENKES RI. Situasi gangguan penglihatan dan kebutaan. Pusat Data dan Informasi (Infodatin) Kementerian Kesehatan RI. 2014. [cited 2017 Februari 27]. Available from https://www.google.co.id/?

gws_rd=cr,ssl\&ei=ToETV9a0NuHEmwX7to $\mathrm{zgBg} \# \mathrm{q}=$ infodatin +2014

[5] Kabupaten Jember. Dinas Kesehatan Kabupaten Jember. Angka kesakitan katarak Wilayah Kerja Puskesmas SeKabupaten Jember tahun 2016. Jember: Dinas Kesehatan Kabupaten Jember; 2016.

[6] Dewi RM. Contraints and supporting factor to access free cataract surgery: Universitas Airlangga. [Internet]. 2010 [cited 2017 March 2]. Available from journal.unair.ac.id

[7] Tomb DA. Buku saku psikiatri. Jakarta: EGC; 2004

[8] Erman I. Hubungan umur dan jenis kelamin dengan kejadian katarak di Instalasi Rawat Jalan (Poli Mata) Rumah Sakit DR. Sobirin Kabupaten Musi Rawas; Politeknik Palembang. [Internet]. 2014 [cited 2017 June 9]. Available from https://www.scribd.com/doc/306966548/jur nal-katarak-pdf.

[9] Hanok MS, dkk. Faktor-faktor yang berhubungan dengan kejadian katarak di Balai Kesehatan Mata Masyarakat (BKMM)
Provinsi Sulawesi Utara. Sulawesi Utara. [Internet]. 2014 [cited 2017 July 22]. Available from https://www.scribd.com/document/33709 1451/JURNAL-MEISYE-pdf

[10] Ulandari N. Pengaruh pekerjaan terhadap terjadinya katarak pada pasien yang berobat di Balai Kesehatan Mata Masyarakat Nusa Tenggara Barat. [Internet]. 2014 [cited 2017 June 22]. Available from http://www.pps.unud.ac.id/thesis/pdf_the sis/unud-1070-697482586-tesis.pdf _

[11] Tana L., Rifa'i L, dan Ghani L. Peranan pekerjaan terhadap kejadian katarak pada masyarakat indonesia. Riset Kesehatan Dasar 2007; Jakarta. [Internet]. 2009 [cited 2017 June 9]. Available from http://ejournal. litbang.depkes.go.id/index.php/BPK/artic le/download/2196/1094.Serial online

[12] Stauri S. Pengaruh pendidikan kesehatan metode demonstrasi terhadap tingkat pengetahuan dan motivasi penggunaan Alat Pelindung Diri (APD) pada petani desa wringin telu Kecamatan Puger Kabupaten Jember. Jember: Universitas Jember. [Internet]. 2015 [cited 2017 March 2]. Available from http://repository.unej.ac.id/handle/

[13] Siagian SP. Teori motivasi dan aplikasinya. Jakarta: Rineka Cipta; 2004.

[14] Swasti KG. Pengaruh terapi suportif terhadap ansietas siswa kelas XII SMAN 1 Kutasari dalam menghadapi ujian nasional. Tesis: Depok. [Internet]. 2011[cited 2017 March 18]. Available from onlinehttp://lib.ui.ac.id/file? file=digital $/ 20281671 \mathrm{~T} \% 20 \mathrm{keksi}$ \%20Girindra\% \%20Swasti.pdf .

[15] Budiningtyas DK. Pengaruh terapi suportif terhadap intensi melakukan operasi katarak pada pasien katarak di wilayah kerja Puskesmas Tempurejo Kabupaten Jember. Jember: Universitas Jember. [Internet]. 2016 [cited 2017 March 20]. Available from http://repository.unej.ac.id/handle/12345 6789/79433 .

[16] Rahmadani M. Pengaruh terapi psikoedukasi terhadap motivasi untuk operasi katarak pada klien katarak di wilayah kerja Puskesmas Semboro Kabupaten Jember. Jember; Universitas Jember. [Internet] 2016 [cited 25 March 2017]. Available from 
Siswoyo, et al. Terapi Suportif Meningkatkan Motivasi untuk Melakukan Operasi Katarak...

http://repository.unej.ac.id/handle/1234567 89/75746

[17] Smeltzer SC \& Bare BG. Buku ajar keperawatan medikal bedah brunner \& suddarth. Jakarta: EGC; 2002.

[18] Suarli SB. Manajemen keperawatan dengan pendekatan praktik. Jakarta: Erlangga; 2009.

[19] Potter PA, Perry AG. Buku ajar fundamental keperawatan: konsep, proses, dan praktik. Volume 1 edisi 4. Jakarta:
EGC; 2005.

[20] Sunarti N. Tipe kepribadian, tingkat pendidikan, status sosial ekonomi dan ide bunuh diri [internet]. 2012 [diambil tanggal 1 Juni 2016]. dari: http://eprints.ums.ac.id/18965/29/Naska hPublikasi.pdf 